\title{
Carcinoma da Tireóide com Diferenciação Semelhante a Timo (CASTLE): Relato de Caso e Revisão da Literatura
}

\section{apresentação de caso}

\author{
TÂNIA A. RODRIGUES \\ ANTÓNIO G. QUINTELA \\ RICARDO M. LUZ \\ DOLORES LóPEZ
}

Serviço de Oncologia Médica do Hospital Santa Maria, Lisboa, Portugal (TAR, AGQ, RML);

Serviço de Anatomia Patológica do Hospital Santa Maria, Lisboa, Portugal (DL).
Recebido em 12/09/2007

Aceito em 22/01/2008

\author{
RESUMO
}

O carcinoma com diferenciação semelhante a timo (CASTLE) é uma neoplasia epitelial maligna rara, que surge nos tecidos moles do pescoço ou na glândula tireóide. $O$ diagnóstico diferencial deve ser estabelecido com carcinoma pavimento-celular primário ou secundário da cabeça e do pescoço ou da tireóide, visto que têm prognósticos distintos. A imunorreatividade para CD5 pode ser útil no diagnóstico de CASTLE. O CASTLE possui elevada taxa de recidiva local, apesar de o seu curso clínico indolente, ao contrário das neoplasias previamente referidas, que têm um prognóstico muito reservado, dada a elevada taxa de disseminação sistêmica. $O$ tratamento inclui excisão cirúrgica e radioterapia. A quimioterapia também tem sido realizada, apesar de até a presente data não existir evidência clara da sua eficácia. Relata-se caso de doente de sexo masculino, com 52 anos, que surge com tosse seca, disfonia e massa da tireóide, que foi submetido à tireoidectomia. $O$ exame anatomopatológico da peça operatória permitiu o diagnóstico de CASTLE. O doente efetuou radioterapia e quimioterapia e obteve resposta mínima. Pretende-se discutir o diagnóstico anatomopatológico diferencial e a abordagem terapêutica mais adequada de uma patologia com prognóstico favorável, mas de natureza recidivante, que exige seguimento rigoroso a longo prazo.

(Arq Bras Endocrinol Metab 2008; 52/3:550-555)

Descritores: CASTLE; Tireóide; Quimioterapia; Radioterapia

\section{ABSTRACT}

\section{Thyroid Carcinoma with Thymus-Like Differentiation (CASTLE): Case Report and Review of the Literature.}

Carcinoma with thymus-like differentiation (CASTLE) is a rare malignant epithelial tumor wich arises on soft tissue of the neck or thyroid gland. It is important to differentiate CASTLE from primary or metastatic squamous cell carcinoma of head and neck, and from squamous cell thyroid carcinoma, because it has a different prognosis. CD5 immunoreactivity might be helpful in CASTLE diagnosis. CASTLE behaves generally in an indolent fashion, even though it has a high relapse rate, while the other have a dismal prognosis due its high dissemination rate. Treatment includes surgical excision and radiotherapy. Chemotherapy can be offered, although its efficacy is not clear. Authors present a case of a 52 year-old male that complaints with cough, disphony, asthenia, and thyroid mass. Thyroidectomy was performed and the pathology revealed a CASTLE. After radiotherapy and chemotherapy, minimal response was obtained. The authors intend to discuss the differential pathologic diagnosis and the best therapy of this indolent but recurrent neoplasm, that demands strict long term follow-up. (Arq Bras Endocrinol Metab 2008; 52/3:550-555)

Keywords: CASTLE; Thyroid; Chemotherapy; Radiotherapy 


\section{INTRODUÇÃO}

CARCINOMA COM DIFERENCIAÇÃO semelhante a timo

(CASTLE) é uma neoplasia epitelial maligna rara, que surge nos tecidos moles da cabeça e do pescoço ou na glândula tireóide $(1,2)$. Até a presente data, foram reportados 58 casos na literatura inglesa, e apenas um deles não envolvia a glândula tireóide (3).

O CASTLE é uma neoplasia histologicamente semelhante ao carcinoma tímico, nomeadamente do subtipo linfo-epitelial ou pavimentoso. Tem origem nos remanescentes das bolsas branquiais que sofrem diferenciação tímica e subseqüente transformação maligna $(1,4)$. Surge habitualmente na porção média ou inferior da glândula tireóide em adultos, na quinta década de vida. Pode invadir os tecidos adjacentes e metastatizar para os gânglios linfáticos regionais (4-8).

O diagnóstico diferencial de CASTLE com o carcinoma pavimento-celular primário ou secundário da cabeça e do pescoço ou da tireóide é fundamental, visto que têm prognósticos distintos. O tumor de CASTLE possui curso clínico indolente apesar de a elevada taxa de recidiva local, ao contrário das neoplasias previamente referidas, que têm prognóstico muito reservado $(1,5)$.

\section{RELATO DE CASO}

Doente de sexo masculino, 52 anos, raça negra, natural de Cabo Verde, policial, com história familiar de bócio, hábitos tabagísticos acentuados desde os 16 anos de idade e antecedentes pessoais de nódulo da tireóide detectado aos 42 anos. Surge, sete anos depois, com quadro clínico caracterizado por tosse seca, disfonia, astenia e aumento progressivo das dimensões do nódulo da tireóide. No exame objetivo, apresentava massa cervical anterior esquerda móvel com os movimentos da deglutição, indolor, heterogênea e de consistência aumentada à palpação, sem adenopatias periféricas loco-regionais palpáveis. Analiticamente, não se registraram alterações relevantes, nomeadamente das provas de função tireóide.

A radiografia de tórax (Figura 1) mostrava alargamento da silhueta mediastinal e na tomografia computorizada (TC) do pescoço era descrito bócio mergulhante. Foi referenciado do hospital do país de origem ao Serviço de Cirurgia Cardiotorácica da nossa instituição, para realizar tireoidectomia que foi parcial, dada a invasão tumoral loco-regional detectada durante a cirurgia.

No estudo anatomopatológico da peça operatória, observou-se infiltração da tireóide por tecido de

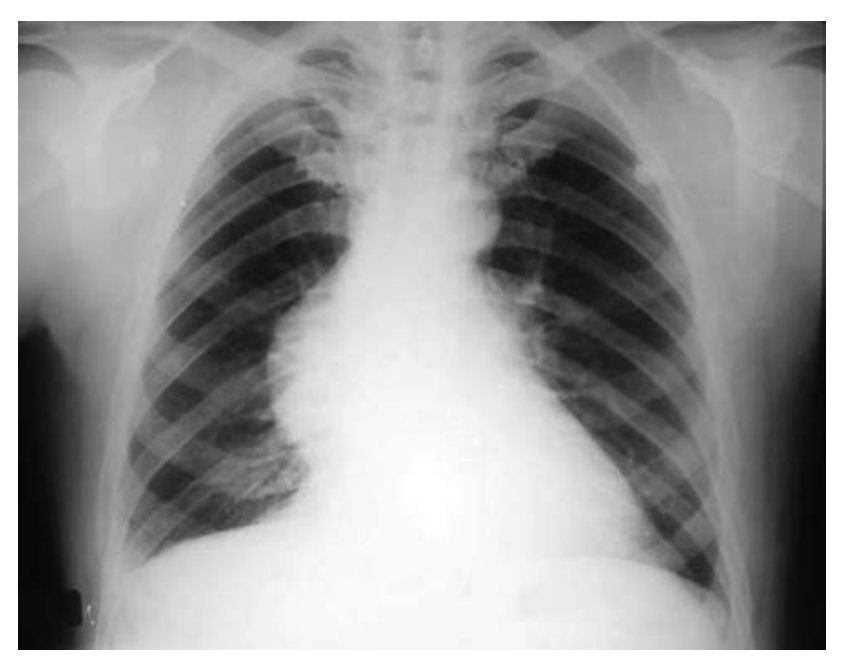

Figura 1. Radiografia do tórax.

neoplasia constituída por células grandes com núcleos vesiculosos e nucléolos proeminentes; as células estavam dispostas em toalhas, constituindo lóbulos separados por estroma desmoplásico e infiltração moderada por linfócitos; havia focos de necrose e figuras de mitose. No estudo imunohistoquímico verificou-se imunorreatividade das células neoplásicas para citoqueratina-beta E12, CD5 e bcl-2. O diagnóstico foi de CASTLE (Figura 2).

As TC do pescoço e do toráx, efetuadas no pósoperatório, confirmaram a presença de tumor residual, caracterizado por massa mediastinal com $6 \mathrm{~cm}$ de maior diâmetro, com ponto de partida no lobo esquerdo da tireóide, que se estendia do opérculo torácico até à emergência dos grandes vasos do pescoço, desviando a traquéia para a direita. Após colocação de prótese endotraqueal, o doente foi submetido à radioterapia externa (dose total de 60 Gy).

Sete meses depois da cirurgia, perante evidente crescimento tumoral loco-regional, que condicionava invasão da traquéia, do esôfago e da veia jugular interna esquerda (Figura 3), o doente foi referenciado ao Serviço de Oncologia Médica. Iniciou quimioterapia com carboplatina e etoposido, e após dois ciclos verificou-se estabilização da doença. Decide-se, então, realizar outro esquema de quimioterapia, para obter resposta máxima. Foram realizados seis ciclos de cisplatina, bleomicina e vimblastina. Após quatro ciclos, seis meses após o início da quimioterapia, e 11 meses após o diagnóstico, verificou-se resposta mínima (Figura 4). Treze meses após o diagnóstico, o doente permanecia assintomático, apresentava bom estado geral e tolerava a quimioterapia sem toxicidade significativa. 

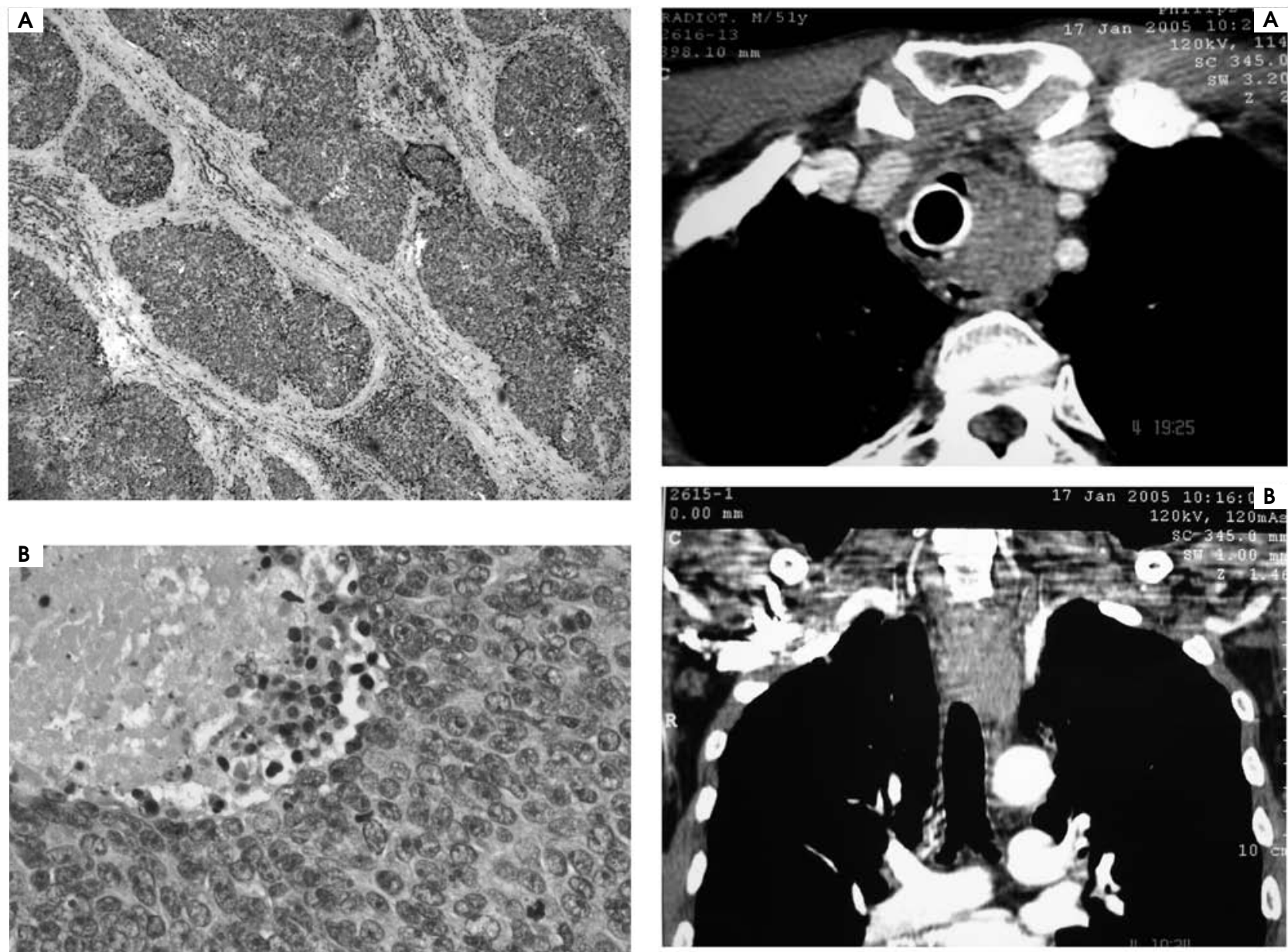

Figura 3. Tomografia de pescoço.

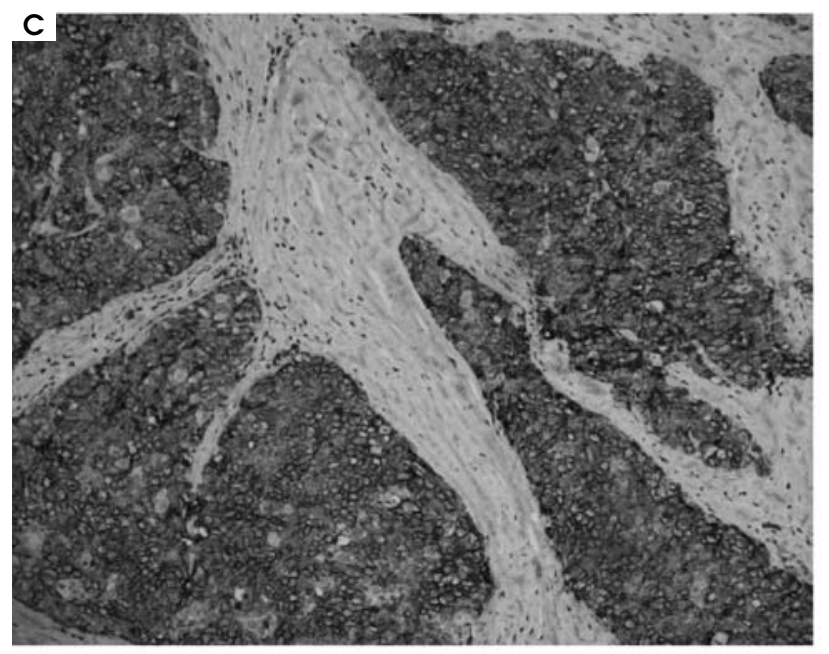

Figura 2. Exame anatomopatológico.

\section{DISCUSSÃO}

Estão reportados na literatura tumores raros que surgem nos tecidos moles da cabeça e do pescoço e na glândula tireóide que mostram características histológicas semelhantes às do timo involuído, fetal ou maduro, e à de timomas mediastínicos (1). Segundo Chan e Rosai, constituem um espectro alargado de lesões que se estende desde neoplasias clinicamente benignas, bem diferenciadas, como o timoma hamartomatoso ectópico e o timoma cervical ectópico, até lesões malignas, mal diferenciadas, com freqüente invasão loco-regional, e potencial de metastatização, em que se incluem: spindle epitelial tumor with thymus-tike diferentiation (SETTLE) e carcinoma showing thymus-like diferentiation (CASTLE) $(1,4)$. 

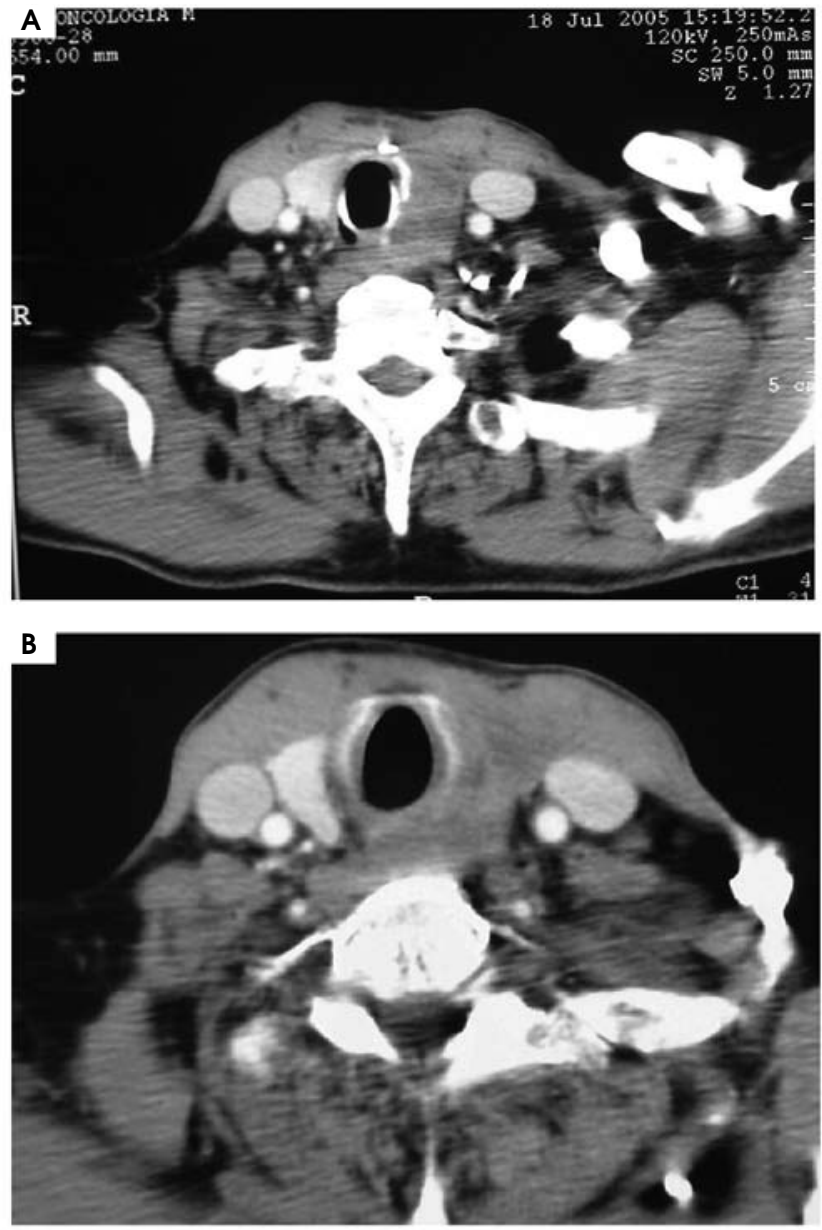

Figura 4. Tomografia de pescoço.

O CASTLE foi pela primeira vez descrito por Miyauchi e cols., como timoma epitelial intratireóideo (ITET) (5). Surge habitualmente como uma massa cervical intra ou extratireóide, em adultos na quinta década de vida, contudo, em razão do número limitado de casos, não está determinada a predominância de raça ou sexo. Não estão descritos sintomas específicos, mas pode surgir disfonia por envolvimento do nervo laríngeo recorrente (3). O diagnóstico é fundamentalmente histopatológico, as características são semelhantes às do carcinoma tímico e incluem septos fibrosos intersectando cordões e lóbulos de células tumorais, infiltrados de pequenos linfócitos e plasmócitos, e aglomerados focais de células pavimentosas semelhantes a corpúsculos de Hassall. As células tumorais são poligonais e fusiformes com citoplasma eosinófilico abundante de bordos bem definidos, com núcleos redondos ou ovais com cromatina dispersa e nucléolos proeminentes. $\mathrm{O}$ índice mitótico é relativamente baixo ( $1-4)$.

A imunorreatividade para CD5 tem sido reportada no carcinoma tímico mas também no CASTLE intratireóideo (2-4). Dorfman e cols. detectaram imunorreatividade para CD5, quer em tumores primários, quer em metástases ganglionares e pulmonares, de ITET/CASTLE (6). Pelo contrário, nos carcinomas pavimentosos da tireóide, e em outros carcinomas pavimentosos da cabeça e do pescoço esta imunorreatividade não foi detectada $(7,8)$. Vários autores concluíram que a imunorreatividade para CD5 suporta a diferenciação tímica desta neoplasia (6-8). A imunorreatividade para bcl-2 e mcl- 1 foi detectada em vários casos de tumores de ITET/CASTLE, e de carcinoma tímico (4). A presença destes proto-oncogenes antiapoptoses nos carcinomas tímicos verdadeiros e em uma minoria de timomas já era conhecida (9-12). Ficou demonstrado que a imunorreatividade bcl-2 e mcl-l é uma característica das neoplasias de diferenciação tímica em geral, quer no timo, quer em localização ectópica (4).

No que diz respeito ao diagnóstico diferencial, o CASTLE distingue-se do SETTLE pela idade do doente e das características histológicas. O SETTLE surge em crianças e adultos jovens; histologicamente tem padrão lobular; e é constituído por células fusiformes e células com diferenciação epitelial $(1,2)$. De acordo com Cheuk e cols., tem um potencial de metastatização de cerca de 70\% e não expressa CD5 (13). É fundamental ainda excluir outras neoplasias de prognóstico reservado, como carcinoma primário indiferenciado ou pavimentoso da tireóide, carcinoma pavimentoso da cabeça e do pescoço e metástases de carcinoma de origem desconhecida, particularmente do tubo digestivo, vias aéreas, pulmão e mediastino $(1,4,5)$.

Cheng-Ming e cols. estudaram o total de 26 casos reportados e verificaram que 10 tiveram recidiva após tratamento, e que a maioria das recidivas se evidenciou em doentes com metástases ganglionares cervicais ou invasão dos tecidos adjacentes (3). O tempo até a recidiva variou entre 3 meses e 17 anos $(1,3,5,14)$. Assim, é importante realizar o seguimento por longo período.

A terapêutica do tumor de CASTLE consiste em excisão cirúrgica associada ou não a radioterapia $(1,3)$. A radiossensibilidade do CASTLE e o seu caráter recidivante local tem fundamentado a realização de radioterapia pós-operatória com intuito de reduzir a taxa de 
recidiva $(3,15,16)$. Em uma revisão de 22 casos realizada por Roka e cols., foi observado maior número de recidivas locais em doentes tratados apenas com cirurgia (7 de 10 doentes), comparativamente aos sujeitos a cirurgia e radioterapia externa ( 1 de 5 doentes). A quimioterapia foi realizada em alguns doentes com resposta muito variável. Apenas uma resposta completa, após tratamento com docetaxel e cisplatina, foi obtida em um doente com doença metastática (17).

Em outra revisão, realizada por Kusada e cols., verificou-se que cinco dos 26 doentes faleceram com CASTLE, apesar de, em 50\% dos casos (13 de 26), a RT ter sido efetuada (18). Cheng-Ming e cols. verificaram que a maioria das recidivas ocorria em doentes com adenopatias cervicais positivas (3).

De acordo com Chow e cols., a tireoidectomia total combinada com quimioterapia e radioterapia é eficaz no controle local e no alívio da sintomatologia. Etoposido e carboplatina foram fármacos ministrados a alguns doentes, que obtiveram boa resposta (19).

No caso aqui reportado, mostra-se que a quimioterapia poderá ter um papel importante no controle da doença, ponderando sempre a relação risco-benefício na qualidade de vida do doente. Após documentação de progressão, obtivemos estabilização da doença com o primeiro esquema terapêutico, e com o segundo, resposta mínima, conseguindo manter a doença controlada, sem toxicidade significativa.

A abordagem terapêutica multidisciplinar, incluindo cirurgia, radioterapia e quimioterapia, provavelmente será a melhor opção. A quimioterapia pode ser útil no alívio rápido da sintomatologia, especialmente na redução da massa tumoral, prevenindo a obstrução das vias aéreas, e poderá incluir vários fármacos. Algumas combinações com cisplatina, vimblastina e bleomicina ou doxorrubicina, ciclofosfamida e vincristina, entre outros, incluindo 5-fluoruracil/leucovorina, carboplatina e etoposido, demonstraram eficácia terapêutica no carcinoma tímico (20).

Em resumo, é fundamental diferenciar o CASTLE de outras neoplasias malignas pelas implicações no prognóstico. Pelo seu caráter recidivante e pela possibilidade de metastatização ganglionar loco-regional, após longos intervalos de tempo, o seguimento a longo prazo é crucial $(2,3,5)$. Em alguns casos, as recidivas foram controladas com cirurgia e/ou radioterapia $(1,3)$. Estudos com maior número de doentes seriam fundamentais para esclarecer o papel da quimioterapia no tratamento destas patologias, nomeadamente em estádios mais avançados, com metastatização loco-regional e/ou a distância, o que é difícil, dada a raridade da patologia.

\section{REFERÊNCIAS}

1. Chan JK, Rosai J. Tumors of the neck showing thymic or related branchial pouch differentiation: a unifyng concept. Hum Pathol. 1991;22(4):349-67.

2. Bayer-Garner IB, Kozovska ME, Schwartz MR, Reed JA. Carcinoma with thymus-like differentiation arising in the dermis of head and neck. J Cutan Pathol. 2004;31(9):625-9.

3. Cheng-Ming L, Hsueh C, Chen TM. Extrathyroid carcinoma showing thymus-like differentiation (CASTLE) tumor-a new case report and review literature. Head Neck. 2005;27(10):927-33.

4. Dorfman DM, Shahasafaei A, Miyauchi A. Immunohistochemical staining for bcl-2 and mcl-1 in intrathyroidal epitelial thymoma (ITET)/carcinoma showing thymus-like differentiation (CASTLE) and cervical thymic carcinoma. Mod Pathol. 1998;11(10):989-94.

5. Miyauchi A, Kuma K, Matsuzuka F, Matsubayashi S, Kobayashi A, Tamai, et al. Intrathyroidal epitelial thymoma: an entity distinct from squamous cells carcinoma of the thyroid. World $\mathrm{J}$ Surg. 1985;9:128-35.

6. Dorfman DM, Shahasafaei A, Miyauchi A. Intrathyroidal epithelial thymoma (ITET/carcinoma showing thymus-like differentiation (CASTLE) exhibits CD5 immunoreactivity: new evidence for thymic differentiation. Histopathology. 1998;32(2):104-9.

7. Hishima T, Fukayama M, Fujisawa M, et al. CD5 expression in thymic carcinoma. Am J Pathol. 1994;145:268-75.

8. Arber DA, Weiss LM. CD5: a review. Appl Immunohistochem. 1995;1:1-22.

9. Chen F-F, Yan J-J, Jin YT, Su J-J. Detection of bcl-2 and p53 in thymoma: expression of $\mathrm{b} \mathrm{cl-2}$ as a reliable marker of tumor aggressiveness. Human Pathol. 1996;27:1089-92.

10. Stefanaki K, Rontogianni D, Kouvidou $\mathrm{CH}$, Bolioti S, Delides G, Pantelidaki A, et al. Expression of p53, mdm2, p21/wafl, and bcl-2 proteins in thymomas. Histopathology. 1997;30:549-55.

11. Tateyama $H$, Fimoto $T$, Tada $T$, Inagaki $H$, Hattori $H$, Takino $H$. Apoptosis, bcl-2 protein, and faz antigen in thymic epithelial tumors. Mod Pathol. 1997;10:983-91.

12. Chen FF, Yan JJ, Chang KC, Lai WW, Chien RMY, Jin YT. Immunohistochemical localization of mcl-1 and bcl-2 proteins in thymic epithelial tumors. Histopathology. 1996;29:541-47.

13. Cheuk W, Jacobson AA, Chan JKC. Spindle epithelial tumor with thymus-like element: a distinctive malignant thyroid tumor with significant metastatic potential. Mod Pathol. 2000;13(10):1150-5.

14. Da J, Shi H, Lu J. Thyroid squamous-cell carcinoma showing thymus-like element (CASTLE): a report of eight cases. Chin $\mathrm{J}$ Oncol. 1999;21:303-4.

15. Kakudo K, Mori I, Tamaoki N, Watanabe K. Carcinoma of possible thymic origin presenting as a thyroid mass: a new subgroup of squamous cell carcinoma of the thyroid. J Surg Oncol. 1988;38:187-92.

16. Piacentini MG, Romano F, Fina S, Sartori P, Leone EB, Rubino $B$, et al. Carcinoma of the neck showing thymic-like elements (CASTLE): report of a case and review of the kliterature. Int $J$ Surg Pathol. 2006;14:171-5. 
17. Roka S, Kornek G, Schuller J, Ortmann E, Feichtinger J, Armbruster $\mathrm{C}$. Carcinoma showing thymic-like elements e a rare malignancy of the thyroid gland. Br J Surg. 2004;91:142-5.

18. Kusada N, Hara $Y$, Kobayashi S, et al. A case of aggressive carcinomashowing thymus-like differentiation with distant metastases. Thyroid. 2005;15:1383-8.

19. Chow SM, Chan JKC, Tse LLY, Tang DLC, et al. Carcinoma showing thymus-like element (CASTLE) of thyroid: combined modality treatment in 3 patients with locally advanced disease. Eur J Surg Oncol. 2007;33:83-5.

20. Cameron R, Loehrer P, Thomas Jr C. Neoplasms of the mediastinum. In: De Vita Jr. VT, Hellman S, Rosenberg SA, editores. Cancer principles and practice of oncology. $7^{\mathrm{a}}$ ed. Philadelphia: Lippincott Williams and Wilkins; 2005. p. 851-2.
Endereço para correspondência:

Tânia A. Rodrigues

Alta de Lisboa, R. Shegundo Galarza, Páteo São João de Brito, lote 7.1, bloco 3, $10^{\circ} \mathrm{B}$

1750-436 Lisboa, Portugal

E-mail: taniaarodrigues@gmail.com 